OBSERVATORIO DAS DESIGUALDADES

E-WORKING PAPER N.2/2021

\title{
EMPODERAMENTO POLÍTICO DAS MULHERES EM PERSPETIVA \\ COMPARADA: UMA REVISÃO CRÍTICA DOS ÍNDICES DE GÉNERO
}

FRANCISCA MARTINS REINA 


\section{COMO CITAR}

Reina, Francisca (2021), "Empoderamento político das mulheres em perspetiva comparada: uma revisão crítica dos índices de género", Observatório das Desigualdades e-Working Papers, N²/2021: CIES-Iscte, ISSN 2183-4199, doi: 10.15847/CIESODWP022021.

Disponível em http://observatorio-das- desigualdades.com/working-papers-od/

\section{TíTULO}

Empoderamento político das mulheres em perspetiva comparada: uma revisão crítica dos índices de género

\section{RESUMO}

Este artigo oferece uma revisão crítica dos índices de género existentes e discute a sua adequabilidade para comparar o empoderamento político das mulheres à escala global, à luz dos debates metodológicos recentes na literatura sobre género e política. Apesar da expansão e diversificação deste campo de estudo, em paralelo com a incorporação da igualdade de género na agenda política internacional, as abordagens quantitativas para a análise do empoderamento político das mulheres mantiveram um escopo limitado. Os índices de género das organizações internacionais medem somente a representação parlamentar das mulheres, revelando-se inadequados para compreender a diversidade de experiências de empoderamento político das mulheres. Em alternativa, proponho o uso do Índice do Empoderamento Político das Mulheres (WPEI) do V-Dem, composto por três dimensões: liberdades civis, participação na sociedade civil e participação política. Para demonstrar a sua aplicabilidade, recorro a dados empíricos de países do Médio Oriente e Norte de África.

Palavras-chave: Empoderamento político das mulheres, Género, Política, Índices de género 


\section{TÍTLE}

Women's political empowerment in comparative perspective: a critical review of gender indices

\section{ABSTRACT}

This article provides a critical review of existing gender indices and discusses its appropriateness to compare women's political empowerment across the globe, in light of recent methodological debates on gender and politics. Despite the expansion and diversification of this subfield, in parallel with the incorporation of gender equality on the international agenda, quantitative approaches to the analysis of women's political empowerment maintained a limited scope. Gender indices from international organisations only measure female parliamentary representation, proving inadequate to grasp the diverse experiences of women's political empowerment. Alternatively, I suggest the use of the V-Dem Women's Political Empowerment Index (WPEI), which is composed of three dimensions: civil liberties, participation in civil society and political participation. To demonstrate its applicability, I draw on empirical data from Middle Eastern and North African countries.

Keywords: Women's political empowerment, Gender, Politics, Gender indices 



\section{ÍNDICE}

Índice de quadros, gráficos e figuras.

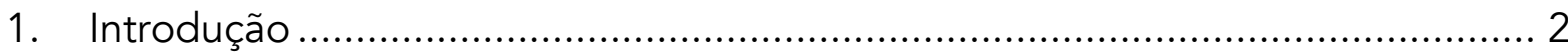

2. Análise comparada do empoderamento político das mulheres: principais abordagens e desafios

3. Índices de género e suas limitações …………............................................... 7

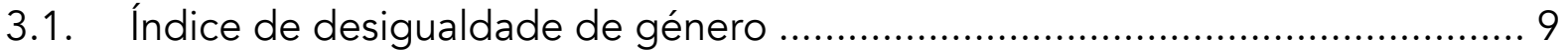

3.2. Índice global das disparidades de género ................................................. 10

3.3. Índice das instituições sociais e género.................................................... 13

4. Novos contributos: o índice do empoderamento político das mulheres.......... 15

4.1. Análise empírica do empoderamento político das mulheres ........................ 19

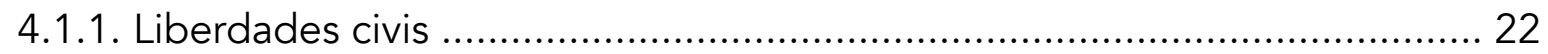

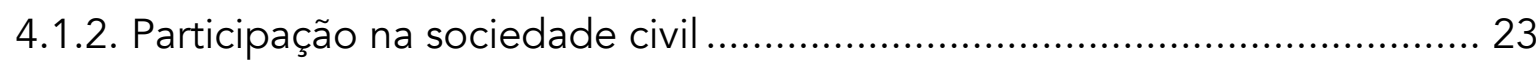

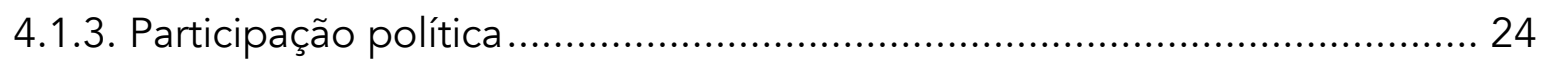

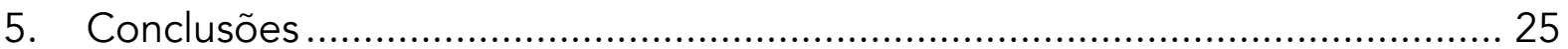

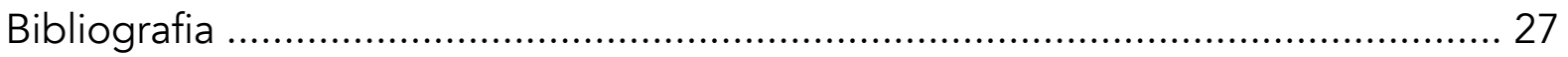

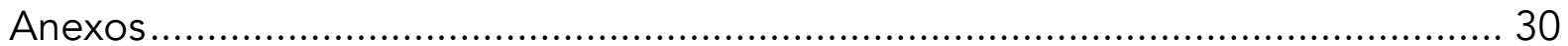




\section{ÍNDICE DE QUADROS, GRÁFICOS E FIGURAS}

\section{QUADROS}

Quadro 1. Síntese do Índice do Empoderamento Político das Mulheres

FIGURAS

Figura 1. Empoderamento político das mulheres por região, 2020 .................................. 19

Figura 2. Empoderamento político das mulheres (WPEI), MONA, 1995-2020 .................. 20

Figura 3. Dimensões do empoderamento político das mulheres, MONA, 2020 ................ 21

Figura 4. Liberdades civis das mulheres, MONA, 1995-2020 ........................................ 22

Figura 5. Participação das mulheres na sociedade civil, MONA, 1995-2020...................... 23

Figura 6. Participação política das mulheres, MONA, 1995-2020...................................... 24 


\section{EMPODERAMENTO POLÍTICO DAS MULHERES EM PERSPETIVA COMPARADA: UMA REVISÃO CRÍTICA DOS ÍNDICES DE GÉNERO ${ }^{1}$}

Francisca Reina

Estudante do $3^{\circ}$ Ano da Licenciatura em Ciência Política e Relações Internacionais na Faculdade de Ciências Sociais e Humanas da Universidade Nova de Lisboa (Nova FCSH).

\section{INTRODUÇÃo}

Uma das alterações globais mais significativas na transição para o novo milénio foi a crescente incorporação da igualdade de género na agenda política internacional, impulsionada pela adoção da Plataforma de Ação de Pequim em 1995. Um dos objetivos previstos no documento é o de desenvolver e melhorar os métodos utilizados na recolha e análise de dados sobre desigualdades de género à escala global (United Nations, 1996). Com efeito, o esforço conjunto de cientistas sociais e profissionais na área do desenvolvimento e dos direitos humanos resultou na criação de indicadores de género relevantes para avaliar o progresso dos estados relativamente às metas estabelecidas.

Os índices de género desenvolvidos por organizações internacionais e regionais como as Nações Unidas ou a União Europeia sofrerem diversas alterações ao longo do tempo. Não existe um consenso sobre a definição de conceitos como

\footnotetext{
${ }^{1}$ Gostaria de agradecer os comentários e sugestões da equipa do Observatório das Desigualdades, bem como os pareceres dos/as revisores/as anónimo/as pelo seu contributo fundamental para o aperfeiçoamento deste artigo.
} 
"(des)igualdade de género" ou "empoderamento das mulheres", isto é, sobre os atributos que um país deve cumprir para poder ser classificado como mais ou menos (des)igual em termos de relações género. Por esse motivo, cada índice conceptualiza e operacionaliza o fenómeno de forma diversa, incluindo dimensões e indicadores que outras medidas excluem.

No que diz respeito às desigualdades políticas de género, os índices globais não acompanharam os contributos cada vez mais numerosos e diversificados dos estudos de género e política (Paxton et al., 2007). Face às críticas movidas no plano académico contra o uso quase exclusivo do indicador da percentagem de mulheres nos parlamentos nacionais, nos anos recentes emergiram novas abordagens para a análise comparada do "empoderamento político das mulheres" (Alexander et al., 2018; Karim \& Hill, 2018; Sundström et al., 2017). Um dos contributos mais relevantes foi a criação de um novo índice global do empoderamento político das mulheres por uma equipa de investigadores do Varieties of Democracy (V-Dem) Institute (Sundström et al., 2017).

Nesse sentido, o principal objetivo deste artigo é avaliar a adequabilidade dos índices de género para a análise comparada do empoderamento político das mulheres. Uma medida adequada, que garante uma comparação rigorosa e significativa entre um elevado número de países e regiões, deve cumprir dois requisitos básicos: 1) possuir uma cobertura espacial e temporal suficientemente extensa e consistente, sem lacunas de dados significativas (o que depende dos recursos disponíveis para a recolha e tratamento dos dados); e 2) ser uma medida válida e precisa para o conceito a partir do qual foi construída, (preferencialmente enquadrado numa teoria ou hipótese a ser testada), mas também sensível à diversidade de contextos e experiências das mulheres à escala global.

Na secção inicial, introduzo de forma sucinta as principais abordagens e desafios na análise do empoderamento político das mulheres. Em seguida, comparo três índices de género, desenvolvidos por organizações internacionais, quanto à sua 
adequabilidade para o estudo dos níveis de empoderamento político das mulheres à escala global, discutindo as suas principais limitações. Na terceira secção, demonstro a aplicabilidade e pertinência do Índice do Empoderamento Político das Mulheres (WPEI) com base nos dados de oito países do Médio Oriente e Norte de África. Na secção final, apresento as principais conclusões deste estudo, enfatizando as potencialidades do WPEI face aos restantes índices de género e discutindo as suas limitações.

\section{ANÁlise COMPARADA DO EMPODERAMENTO POLÍTICO DAS MULHERES: PRINCIPAIS ABORDAGENS E DESAFIOS}

No momento de analisar as (des)igualdade de género ou o empoderamento das mulheres com recurso aos índices globais, é importante distinguir as posições teóricas e analíticas que inspiraram a construção destas medidas. De acordo com Laura de Bonfils et al. (2016), existem três abordagens gerais para analisar a igualdade de género: 1) a igualdade de oportunidades, que implica o acesso e a participação igualitária das mulheres em domínios tradicionalmente masculinos (como a representação política); 2) a valorização igual da diferença, com o reconhecimento dos contributos diferentes de homens e mulheres para uma sociedade organizada em hierarquias de género; 3) a transformação das relações e papéis de género, com a criação de formas de organização social independentes do género.

Geralmente, a escolha da abordagem depende não só da (in)disponibilidade dos dados, mas também dos motivos que presidiram à sua recolha e análise. Uma organização internacional como as Nações Unidas procura monitorizar os progressos alcançados no domínio da igualdade de género, pelo que a composição do índice reflete as inclinações e compromissos políticos dos estados. No contexto académico, a construção de índices de género serve geralmente o propósito de testar uma teoria 
ou hipótese, que justifica uma preocupação acrescida com a definição de conceitos e a construção de indicadores comparáveis no espaço e no tempo.

Até aos anos recentes, nos estudos de género e política, proliferavam os contributos sobre a representação e participação política das mulheres, enquanto outras dimensões da desigualdade de género na política permaneceram pouco estudadas (Paxton et al., 2007; Paxton \& Hughes, 2014), como os direitos das mulheres, a participação na sociedade civil e a violência contra as mulheres. Para Zehra Arat (2015), a preferência por indicadores como a percentagem de mulheres nos parlamentos nacionais (mais evidente nos índices de género das Nações Unidas) é consequência do domínio internacional do feminismo liberal. Em linha com a primeira abordagem identificada por Bonfils et al. (2016), esta corrente do pensamento feminista prioriza a integração das mulheres nas estruturas masculinas do poder, entendido como uma propriedade detida pelos indivíduos (e não como uma relação de poder entre indivíduos e grupos). Um dos problemas desta conceção apontado por Arat (2014) é o pressuposto de que o acesso ao poder por algumas mulheres (por exemplo, representantes eleitas em órgãos de poder) possibilita automaticamente o empoderamento de todas as mulheres, ignorando a diversidade de estruturas de subordinação e marginalização existentes na sociedade.

A expansão e diversificação dos estudos feministas na sociologia, ciência política e relações internacionais trouxe consigo uma redefinição das noções de género, poder e política. Um contributo recente a destacar é o de Amy C. Alexander, Catherine Bolzendahl e Farida Jalalzai (2018), num volume inteiramente dedicado ao desenvolvimento de abordagens teóricas e metodológicas para a compreensão do empoderamento político das mulheres à escala global. As autoras definem teoricamente o empoderamento político global das mulheres como um processo de "melhoria dos recursos, capacidades e ganhos das mulheres para alcançar a igualdade em relação aos homens na influência e exercício da autoridade política à escala mundial" [tradução livre] (Alexander et al., 2018, p. 4). Na sua perspetiva, se a 
construção do género opera ao nível individual, comunitário e institucional, também as medidas do empoderamento das mulheres devem considerar as capacidades e oportunidades individuais (conhecimento político, acesso, direitos), os fatores comunitários (mobilização política, campanha eleitoral, representação local) e as arenas institucionais mais vastas (eleições nacionais, lobbies e organizações políticas, poder e liderança nos cargos políticos).

De acordo com Sabrina Karim e Danny Hill (2018), uma das consequências indesejadas do desenvolvimento dos estudos de género e política foi a distorção do conceito de (des)igualdade de género, amplamente utilizado como sinónimo para várias dimensões da condição da mulher numa sociedade. Para os autores, a (des)igualdade de género é um conceito difícil de mensurar porque se relaciona com a construção social de identidades masculinas/femininas em oposição entre si e com a (desconstrução da) (re)produção do poder dominante. Em alternativa, propõem o uso de conceitos como inclusão, segurança e direitos das mulheres, pela sua adequabilidade a comparações que envolvem um elevado número de casos.

Ainda assim, um dos principais desafios da análise empírica do empoderamento político das mulheres à escala global continua a ser a integração das diferenças entre mulheres de vários países e de grupos (raciais, étnicos, religiosos, nacionais) do mesmo país. A "interseccionalidade", termo cunhado por Kimberle Crenshaw (1991) para teorizar a intersecção entre sistemas de opressão de género e de raça, é uma abordagem que rejeita a visão das mulheres como grupo monolítico e questiona as estruturas de poder que (re)produzem as desigualdades sociais. De acordo com esta perspetiva, a interação entre hierarquias de género, etnicidade ou classe produz uma "matriz de dominação" através da qual os indivíduos experienciam simultaneamente privilégio e opressão ou múltiplas opressões (Arat, 2015; Hughes \& Dubrow, 2018).

Uma análise interseccional altera substancialmente a forma como o empoderamento político das mulheres é entendido, i.e., não como um processo simples e linear, mas como um fenómeno complexo, contingente e variado. 
Contudo, ao basear-se numa análise das relações de poder, a interseccionalidade coloca novos desafios de mensurabilidade, desde logo porque as identidades são complexas e relacionais (não podendo ser reduzidas a atributos demográficos), mas também pela dificuldade em observar o funcionamento das estruturas de subordinação num elevado número de países e anos (Hughes, 2019; Hughes \& Dubrow, 2018).

\section{3. ÍNDICES DE GÉNERO E SUAS LIMITAÇÕES}

Como demonstrado na secção anterior, os índices de género obedecem a diferentes propósitos e espelham diferentes abordagens analíticas e conceptuais, algumas delas pouco explícitas e rigorosas. No entanto, é possível identificar semelhanças entre as medidas existentes, sobretudo no que diz respeito à medição do empoderamento político das mulheres. Uma delas é o predomínio de variáveis relacionadas com a representação descritiva das mulheres nas instituiçõos políticas, em linha com as premissas fundamentais do feminismo liberal (Arat, 2015; Karim \& Hill, 2018).

De acordo com Senem Ertan et al. (2018), existem três categorias de medidas do empoderamento político das mulheres. A primeira refere-se às medidas desenvolvidas pelas Nações Unidas, incluindo o Índice de Desenvolvimento de Género (GDI), a Medida de Empoderamento de Género (GEM), o Índice de Desigualdade de Género (GII) ou, ainda, o Índice das Normas Sociais de Género $(\mathrm{GSNI})^{2}$. A segunda categoria inclui as medidas utilizadas por outras agências

\footnotetext{
${ }^{2}$ Originalmente Gender Social Norms Index (GSNI), este índice foi introduzido em 2019 no relatório anual do Programa das Nações Unidas para o Desenvolvimento com o objetivo de medir o impacto das crenças sociais nas desigualdades de género ao longo de quatro dimensões: política, educação, economia e integridade física (UNDP, 2020b). Os dados mais recentes estão disponíveis em http://hdr.undp.org/en/gsni
} 
nacionais e internacionais, entre as quais o Índice da Igualdade de Género $(\mathrm{GEI})^{3}$, o Índice Global das Disparidades de Género (GGGI) ou o Índice das Instituições Sociais e Género (SIGI). Por fim, a terceira categoria é a das medidas desenvolvidas por equipas de investigação, em que se destaca o Índice do Empoderamento Político das Mulheres (WPEI), o Índice Mulheres, Paz e Segurança ${ }^{4}$ (WPSI), entre outras medidas pouco mencionadas na literatura sobre género e política.

Em conformidade, nas secções seguintes, procuro avaliar a adequabilidade dos índices de género existentes para a análise do empoderamento político das mulheres à escala global. Primeiro, discuto as características e limitações de três índices globais desenvolvidos por organizações internacionais: Índice de Desigualdade de Género (GII) das Nações Unidas, o Índice Global das Disparidades de Género (GGGI) do Fórum Económico Mundial, e o Índice das Instituições Sociais e Género (SIGI) da OCDE. A seleção destas três medidas decorre da sua cobertura global, da inclusão de pelo menos uma variável sobre o empoderamento político das mulheres na sua composição e da frequência do seu uso na literatura sobre desigualdades de género. ${ }^{5}$ Numa terceira secção, apresento o Índice do Empoderamento Político das Mulheres (WPEI) do V-Dem Institute como alternativa de medição mais adequada e ilustro a sua aplicabilidade com dados empíricos de países do Médio Oriente e Norte de África.

\footnotetext{
${ }^{3}$ Originalmente Gender Equality Index (GEl), o índice foi desenvolvido pelo Instituto Europeu para a Igualdade de Género (EIGE) com o objetivo de medir o progresso na igualdade de género nos 27 estados-membros da União Europeia. Os dados mais recentes estão disponíveis em https://eige.europa.eu/gender-equality-index/2020

${ }^{4}$ Desenvolvido por dois centros de investigação, Georgetown Institute for Women, Peace and Security (GIWPS) e Peace Research Institute Oslo (PRIO), o Índice das Mulheres, Paz e Segurança - em inglês, Women, Peace and Security Index - mede o bem-estar das mulheres em três dimensões: inclusão, justiça e segurança. O índice cobre um período muito limitado, entre 2017 e 2019 (Klugman et al., 2018).

${ }^{5}$ As outras medidas referidas não cumprem todos estes requisitos. Por exemplo, o Índice das Normas Sociais de Género (GSNI) não possui uma cobertura global, enquanto o Índice da lgualdade de Género (GEI) cobre apenas os países da União Europa. Por seu turno, o Índice Mulheres, Paz e Segurança (WPSI), sendo muito recente, é raramente utilizado na literatura sobre desigualdades de género.
} 
Além de discutir a pertinência dos índices de género à luz da literatura sobre género e política, avalio o seu potencial de comparabilidade, definido tanto pela extensão da sua cobertura espacial e temporal como pela sensibilidade das suas variáveis às diferentes identidades e contextos geográficos que moldam o empoderamento político das mulheres à escala mundial.

\section{1. ÍNDICE DE DESIGUALDADE DE GÉNERO}

O Índice de Desigualdade de Género (GII)6 foi criado pelo Programa das Nações Unidas para o Desenvolvimento (UNDP) em 2010, numa tentativa de ultrapassar as limitações do Índice de Desenvolvimento de Género (GDI)7 e da Medida de Empoderamento de Género (GEM)8, dois índices de género introduzidos em 1995. Os dados mais recentes do Gll incluem indicadores para 189 países, no período compreendido entre 2000 e 2019.

Tal como nos índices anteriores, a construção do Gll segue a abordagem teórica do desenvolvimento humano, que concebe a igualdade de género como uma condição para a realização do potencial de desenvolvimento humano de um país (Gaye et al., 2010). Nesse sentido, o índice procura medir as perdas em desenvolvimento humano que resultam das disparidades entre mulheres e homens

\footnotetext{
${ }^{6}$ Originalmente Gender Inequality Index (GII), os dados deste índice são disponibilizados em relatórios anuais do Programa das Nações Unidas para o Desenvolvimento. Os dados referentes à última edição (UNDP, 2020a) podem ser consultados em http://hdr.undp.org/en/content/gender-inequality-indexgii

${ }^{7}$ Originalmente Gender Development Index (GDI), é uma medida da distribuição por género dos valores do Índice de Desenvolvimento Humano (IDH). Os dados referentes à última edição (UNDP, 2020a) podem ser consultados na seguinte hiperligação: http://hdr.undp.org/en/content/genderdevelopment-index-gdi

${ }^{8}$ Originalmente Gender Empowerment Measure (GEM), mede o acesso das mulheres ao poder político e económico. Os dados deste índice não foram incluídos nas últimas edições do relatório anual do UNDP.
} 
em três dimensões-chave: a saúde reprodutiva, o empoderamento e o mercado de trabalho (UNDP, 2020a).

Uma vez que a escolha dos indicadores está substancialmente dependente da disponibilidade de dados, não existe uma correspondência clara entre as dimensões do índice e os conceitos que apoiam a sua construção. Na verdade, o próprio conceito de "desigualdade de género" não é clarificado pelos autores, sendo implicitamente equiparado às diferenças entre mulheres e homens num conjunto de indicadores.

Por outro lado, no que diz ao empoderamento político das mulheres, o índice apresenta fraca capacidade explicativa. Com efeito, não existe uma dimensão totalmente dedicada à inclusão política das mulheres. A dimensão do "empoderamento" combina dois indicadores distintos: a proporção de mulheres e homens com educação secundária e a proporção de mulheres e homens nos parlamentos nacionais. Discutirei mais adiante a relevância deste último indicador para medir o empoderamento político das mulheres.

\section{2. ÍNDICE GLOBAL DAS DISPARIDADES DE GÉNERO}

Desenvolvido pelo Fórum Económico Mundial em 2006, o Índice Global das Disparidades de Género (GGGI)9 mede as disparidades de género no acesso a recursos e oportunidades. Para esse efeito, o índice utiliza valores relativos (o rácio entre mulheres e homens), ao invés de níveis absolutos de empoderamento das mulheres, avaliando a aproximação dos países ao objetivo da igualdade de género. Os dados do índice estão disponíveis a partir de 2006 para cerca de 156 países.

\footnotetext{
${ }^{9}$ Em inglês, Global Gender Gap Index (GGGI). Os dados do índice são divulgados nos relatórios publicados anualmente pelo Fórum Económico Mundial, disponíveis na seguinte hiperligação: https://www.weforum.org/reports/ab6795a1-960c-42b2-b3d5-587eccda6023
} 
As disparidades de género são medidas numa perspetiva multidimensional, ao longo de quatro categorias (sub-índices): a participação e as oportunidades económicas; os níveis de educação; a saúde e a sobrevivência; e o empoderamento político. À semelhança do Gll, este índice não esclarece o significado de conceitos como "disparidades de género" ou "empoderamento político", selecionando os indicadores com uma cobertura temporal e espacial mais extensa.

A dimensão do empoderamento político das mulheres mede o rácio entre mulheres e homens em três indicadores: a representação em cargos governativos; a representação nos parlamentos; e o número de anos como chefe do executivo (presidente ou primeiro-ministro) nos últimos 50 anos (World Economic Forum, 2021). Subscrevendo os pressupostos do feminismo liberal (Arat, 2015), os autores do Gll e do GGGI consideram a representação em cargos parlamentares e governativos um indicador relevante do empoderamento político das mulheres, na medida em que proporciona a sua integração numa esfera de ação predominantemente masculina.

Ainda assim, há motivos para rejeitar o uso exclusivo destas variáveis - e, por extensão, do Gll e GGGI - no estudo do empoderamento político das mulheres à escala global. Em primeiro lugar, as funções desempenhadas pelos parlamentos variam em função do sistema político do país, pelo que a representação parlamentar feminina não tem a mesma importância (para efeitos de tomada de decisão) em todos os contextos. Geralmente, ela é menos relevante nos sistemas presidenciais, onde será útil verificar a existência de mulheres presidentes; e é mais relevante nos sistemas parlamentares, onde também é importante avaliar a representação feminina no governo e nas comissões parlamentares.

Em segundo lugar, o aumento da representação descritiva das mulheres (através da sua integração nas instituições políticas formais) não se traduz necessariamente numa maior representação substantiva dos interesses das mulheres. Por um lado, o conteúdo desses interesses é variado e não pode ser assumido a priori, sendo o produto da diversidade de experiências e identificações que estratificam a categoria 
"mulheres" em vários grupos. Dessa forma, é importante averiguar se os interesses de diferentes grupos (raciais, étnicos, religiosos, nacionais) de mulheres são amplificados com o aumento da representação feminina nas esferas de decisão ou se apenas as mulheres de grupos sociais dominantes beneficiam desse empoderamento.

Em terceiro lugar, um conjunto de fatores políticos, entre os quais o tipo de regime e a orientação ideológica do governo, determina os limites da capacidade de intervenção e agência das mulheres em cargos políticos. Com efeito, a concentração do poder político num único líder ou órgão de decisão reduz ou inviabiliza a capacidade de influência política das mulheres no parlamento. Além disso, a introdução de medidas destinadas a aumentar a representação política das mulheres (como as quotas eleitorais de género) não reflete necessariamente uma preocupação com a inclusão política das mulheres. Em muitos regimes autoritários, funciona como uma estratégia de apropriação e cooptação da agenda dos direitos das mulheres que permite ao regime definir os termos do debate sobre o empoderamento feminino e/ou projetar no exterior uma aparência de modernização e abertura democrática (Paxton, \& Hughes, 2014).

Finalmente, independentemente do tipo de regime, a participação política formal representa uma entre várias instâncias possíveis do exercício da cidadania política, e não necessariamente a sua arena privilegiada. Uma análise do empoderamento político das mulheres que considera exclusivamente o grau de representação nos órgãos de poder nacionais tende a ser reducionista, ao tornar invisível a participação das mulheres em esferas informais da ação política (por exemplo, nos movimentos sociais e nas organizações da sociedade civil, dedicadas ou não à defesa dos direitos das mulheres). Além disso, os direitos e liberdades civis das mulheres (por exemplo, o direito de associação e manifestação e a liberdade de movimento dentro do país) determinam a sua capacidade efetiva de ação e mobilização política em defesa dos seus interesses. 


\section{3. ÍNDICE DAS INSTITUIÇÕES SOCIAIS E GÉNERO}

O Índice das Instituições Sociais e Género (SIGI)10, desenvolvido pela Organização para a Cooperação e Desenvolvimento Económico (OCDE) em 2009 (e atualizado em 2014), é uma medida da discriminação contra as mulheres nas instituições sociais.

Os autores do SIGI definem as instituições sociais discriminatórias como o conjunto de "leis formais e informais, atitudes e práticas que restringem os direitos e o acesso a oportunidades e recursos de empoderamento a mulheres e raparigas" [tradução livre] (OCDE, 2019). Com base nesta definição, o SIGI avalia qualitativamente as instituições sociais ao longo de quatro dimensões: a discriminação na família, a integridade física restrita, o acesso restrito a recursos produtivos e financeiros, e as liberdades civis restritas.

Enquanto o Gll e o GGGl medem sobretudo os resultados visíveis das disparidades de género em indicadores chave do desenvolvimento humano, o SIGI procura identificar "as bases institucionais da desigualdade de género" (Branisa et al., 2014), referentes ao conjunto de normas e práticas sociais que determinam a distribuição dos papéis de género na sociedade. A abordagem normativa do índice representa, por isso, uma rutura com os índices de género existentes, oferecendo uma perspetiva mais ampla e variada sobre a discriminação das mulheres em contextos geográficos diversos.

Em concreto, a dimensão das liberdades civis restritas, relativa às leis e práticas que condicionam o acesso e a participação das mulheres na esfera pública, oferece dados importantes para o estudo do empoderamento político das mulheres. Codificados numa escala ordinal que capta o grau de discriminação nas instituições, os oito indicadores distribuem-se por quatro áreas distintas:

\footnotetext{
${ }^{10}$ A sigla do índice refere-se à designação original, Social Institutions and Gender Index (SIGI). Os dados podem ser consultados na base de dados Gender, Institutions and Development Database (GID-DB), que contém informação para cada indicador em 180 países (disponível em https://www.genderindex.org).
} 
1) OS DIREITOS DE CIDADANIA: A LEI GARANTE IGUALDADE DE DIREITOS DE CIDADANIA OU NACIONALIDADE E DE CAPACIDADE PARA O SEU EXERCÍCIO;

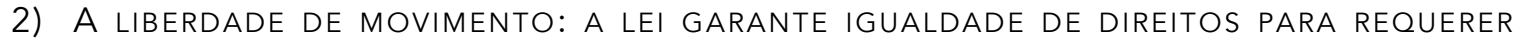
CARTÕES DE IDENTIDADE E PASSAPORTES E VIAJAR PARA O ESTRANGEIRO; A PERCEÇÃO DE SEGURANÇA; ${ }^{11}$

3) A VOZ POLÍTICA: A LEI PROMOVE A REPRESENTAÇÃO POLÍTICA IGUALITÁRIA DAS MULHERES (DIREITO AO VOTO E ACESSO AOS CARGOS PÚBLICOS, ADOÇÃO DE MEDIDAS ESPECIAIS, AUSENNCIA DE PRÁTICAS DISCRIMINATORIAS); A COMPOSIÇÃO DE GÉNERO DOS PARLAMENTOS NACIONAIS; ATITUDES SOBRE A LIDERANÇA POLÍTICA DAS MULHERES; ${ }^{12}$

4) O ACEsso à justiça: a leI garante igualdade de diReitos de testemunho e PROCESSO NO TRIBUNAL E DE OCUPAÇÃO DE CARGOS PÚBLICOS NOS ORGÃOS JUDICIAIS; A CONFIANÇA NO SISTEMA JUDICIAL E NOS TRIBUNAIS. ${ }^{13}$

Esta dimensão do SIGI foi concebida para avaliar a discriminação das mulheres nas instituições responsáveis por garantir o acesso e exercício igualitário das liberdades civis e políticas. Por esse motivo, não será tão adequada para avaliar as suas consequências, i.e., o grau efetivo de participação política e cívica das mulheres. Contudo, revela-se útil para compreender as normas e práticas sociais de género que (re)produzem o acesso desigual ao poder político e aquelas que, inversamente, criam as condições necessárias para o empoderamento político das mulheres em contextos diversos. Por exemplo, os direitos de cidadania e a liberdade de movimento das mulheres, pouco adequados para compreender o estatuto das mulheres no contexto euroamericano (exceto no que diz respeito às mulheres pertencentes a minorias nacionais e étnicas), revelam-se úteis noutros contextos onde a autonomia das mulheres na esfera pública é reduzida.

\footnotetext{
$11 \mathrm{O}$ indicador "perceção segurança" refere-se à percentagem de mulheres que declaram sentir-se inseguras na rua, durante a noite, na sua área de residência, de acordo com o Gallup World Poll (OCDE, 2019).

${ }^{12} \mathrm{O}$ indicador "atitudes sobre a liderança política das mulheres" refere-se à percentagem da população que concorda com a afirmação "Os homens são melhores líderes políticos do que as mulheres", de acordo com o World Values Survey (OCDE, 2019).

${ }^{13} \mathrm{O}$ indicador "confiança no sistema judicial e nos tribunais" refere-se à percentagem de mulheres que declaram não confiar no sistema judicial e nos tribunais do seu país, de acordo com o Gallup World Poll (OCDE, 2019).
} 
Finalmente, se o empoderamento político das mulheres for analisado numa perspetiva histórica comparativa, o SIGI apresenta algumas insuficiências. Apesar da sua cobertura espacial extensa (ao todo, são 180 o número de países abrangidos pelo índice), não é possível comparar longos períodos temporais, só existindo dados para quatro anos recentes (2019, 2014, 2012 e 2009). Essa limitação pode, contudo, ser ultrapassada com o recurso ao Índice do Empoderamento Político das Mulheres (WPEI), que partilha com o SIGI uma dimensão dedicada às liberdades civis das mulheres.

\section{Novos contributos: O Índice do Empoderamento Político das MULHERES}

O Índice do Empoderamento Político das Mulheres (WPEI) ${ }^{14}$, introduzido em 2016 pelo V-Dem Institute ${ }^{15}$, é uma medida especificamente concebida para avaliar o grau de inclusão das mulheres em elementos definidores da democracia ${ }^{16}$, ao contrário dos índices de género analisados na secção anterior.

Os autores do índice definem o empoderamento político das mulheres como "um processo de capacidade crescente para as mulheres, conduzindo a uma maior escolha, agência, e participação na tomada de decisão na sociedade." [tradução livre] (Sundström et al., 2017, p. 2). Em conformidade, o empoderamento político das

\footnotetext{
${ }^{14}$ A sigla refere-se à designação original, Women's Political Empowerment Index.

${ }^{15} \mathrm{O}$ V-Dem Institute, baseado na Universidade de Gotemburgo na Suécia, é responsável pelo V-Dem Dataset, uma base de dados sobre democracia com uma elevada cobertura espacial e temporal, atualizada anualmente por especialistas locais. A última versão (disponível em https://www.v-dem.net), incluía 202 países para um período temporal de 1789-2020, e um total de 483 indicadores, 82 índices, e 5 índices de democracia (Coppedge et al., 2021).

${ }^{16} \mathrm{O}$ facto deste índice tomar como ponto de referência algumas dimensões básicas de um regime democrático não resulta na sua inaplicabilidade a contextos não democráticos, nomeadamente em regimes autoritários com antecedentes democráticos, ou em regimes onde esteja ou tenha estado em curso uma transição democrática.
} 
mulheres é medido ao longo de três dimensões: as liberdades civis (escolha), a participação na sociedade civil (agência), e a participação política (participação).

A primeira dimensão remete para a capacidade de fazer escolhas sobre aspetos fundamentais da sua vida, que implica a existência de um conjunto de direitos e liberdades historicamente negados às mulheres, tais como a liberdade de movimento, o controlo sobre recursos (que inclui a liberdade face ao trabalho forçado e o direito à propriedade) e o acesso à justiça.

A segunda dimensão mede a agência das mulheres, definida como a capacidade de ser um agente ativo na mudança e de expressar publicamente as suas reivindicações. Para isso, algumas condições devem ser garantidas, incluindo a liberdade de discussão e de participação em organizações da sociedade civil e a representação nos órgãos de comunicação social.

Finalmente, a terceira dimensão centra-se na participação das mulheres, entendida como condição essencial para que os interesses das mulheres sejam tidos em conta na tomada de decisão política. Essa participação requer não só a representação das mulheres nos parlamentos nacionais como também uma distribuição igualitária do poder.

O Quadro 1 representa esquematicamente a composição do WPEI, distinguindo as três dimensões e as noves variáveis. Cada dimensão forma um sub-índice, sendo o valor do WPEl calculado pela média aritmética dos valores obtidos para os três subíndices. Tanto o WPEI como os seus sub-índices variam entre 0 e 1, sendo que valores superiores correspondem a um maior grau empoderamento político das mulheres. 
Quadro 1. Síntese do Índice do Empoderamento Político das Mulheres

\begin{tabular}{ll}
\hline Variáveis & Escala \\
\hline Liberdades Civis & $0-4$ \\
\hline Liberdade de movimento das mulheres dentro do país & $0-4$ \\
Liberdade das mulheres face ao trabalho forçado & $0-5$ \\
Direitos de propriedade das mulheres & $0-4$ \\
Acesso à justiça pelas mulheres & \\
\hline Participação na Sociedade Civil & $0-4$ \\
\hline Liberdade de discussão política das mulheres & $0-4$ \\
Participação das mulheres em organizações da sociedade civil & $0-100$ \\
Percentagem de jornalistas mulheres & $0-100$ \\
\hline Participação Política & $0-4$ \\
\hline Percentagem de mulheres no parlamento nacional & \\
\hline Distribuição do poder político por género &
\end{tabular}

As variáveis qualitativas são codificadas numa escala ordinal (entre 0 e 4 ou, na variável "direitos de propriedade das mulheres", entre 0 e 5) que orienta as pontuações atribuídas por especialistas locais e estimadas com base em modelos estatísticos. Por exemplo, a variável "Distribuição do poder político por género" deve ser pontuada de acordo com a pergunta "está o poder político distribuído de acordo com o género?" Os valores são ordenados ao longo de cinco categorias:

- 0: Monopólio Masculino Sobre O Poder Político;

- 1: Domínio Masculino do Poder Político e influência marginal das MULHERES;

- 2: Poder Político Desigualmente Distribuído em Favor Dos homens, Mas As Mulheres mantêm Algumas Áreas de influência;

- 3: Homens Têm Um Poder Político ligeiramente Superior Ao Das Mulheres;

- 4: Poder Político Distribuído de forma Quase igualitária Entre Géneros. 
A conceptualização e operacionalização do WPEI é um dos seus principais pontos fortes, evidenciando a sua adequabilidade para o estudo comparado do empoderamento político das mulheres. Primeiro, a clareza e precisão do conceito de "empoderamento político das mulheres" (e respetivas dimensões) e a justificação teórica da escolha das variáveis (ultrapassando o critério da disponibilidade de dados que norteia os principais índices de género) permitem testar hipóteses teóricas de forma mais rigorosa.

Segundo, à semelhança do SIGI, sendo composto maioritariamente por variáveis qualitativas (com a exceção de duas variáveis quantitativas: a percentagem de mulheres jornalistas e a percentagem de mulheres no parlamento nacional), o WPEI proporciona informação substantiva sobre a natureza do empoderamento político das mulheres. Por exemplo, a inclusão da variável "distribuição de poder por género" na dimensão da participação permite avaliar se a presença feminina na instituição parlamentar se reflete ou não numa expansão de facto da sua capacidade de exercer o poder político. Além disso, esta abordagem qualitativa é mais adequada para captar a diversidade de experiências de empoderamento das mulheres à escala global: os direitos e liberdades civis são aspetos decisivos para a agência de mulheres de diferentes grupos sociais e regiões, incluindo as mulheres do Sul Global pertencentes a minorias raciais, étnicas, nacionais ou religiosas.

Terceiro, concebendo o empoderamento político das mulheres como um processo, os autores do WPEI realçam a importância de captar a mudança ao longo de diferentes períodos históricos (Sundström et al., 2017). Enquanto os principais índices de género cobrem somente os anos mais recentes, oferecendo uma perspetiva estática sobre o empoderamento das mulheres, os dados do WPEI possuem uma cobertura temporal sem paralelo, estendendo-se ao longo de mais de um século (de 1900 a 2020) e abrangendo cerca de 202 países de diferentes regiões. 


\subsection{ANÁLISE EMPÍRICA DO EMPODERAMENTO POLÍTICO DAS MULHERES}

Para ilustrar a aplicabilidade e capacidade explicativa do WPEI, selecionei oito países mediterrânicos do Médio Oriente e Norte de África (MONA), a região com os níveis mais baixos nas três dimensões do empoderamento político das mulheres (Figura 1).

O objetivo é analisar empiricamente a variação interna à região e às dimensões do índice no último quarto de século.

Figura 1. Empoderamento político das mulheres por região, 2020

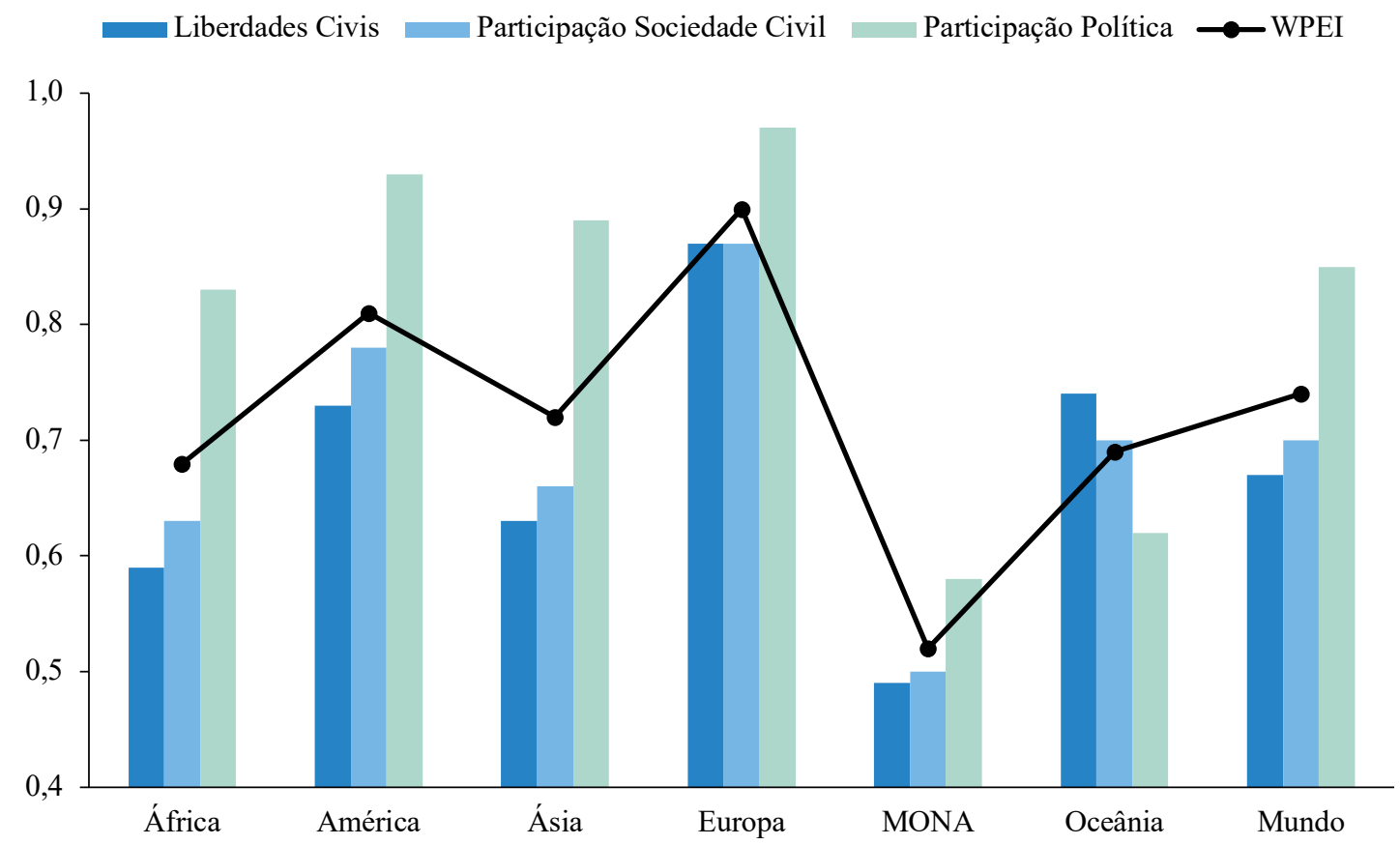

Fonte: V-Dem Dataset v11.1 (Coppedge et al., 2021). 
A Figura 2 representa a evolução do WPEI nos oito países (Argélia, Egito, Jordânia, Líbano, Líbia, Marrocos, Palestina ${ }^{17}$ e Tunísia). Um aspeto a salientar é o progresso verificado nos países do Norte de África, sem par na região. A maior subida dá-se no período da primavera árabe (2011-2012), mas em Marrocos teve início em 2000. Pelo contrário, no Egito, o período entre 2010 e 2015 é marcado por uma descida acentuada dos níveis de empoderamento político das mulheres, seguida de uma subida abrupta que contrasta com a tendência decrescente na região.

Figura 2. Empoderamento político das mulheres (WPEI), MONA, 1995-2020.

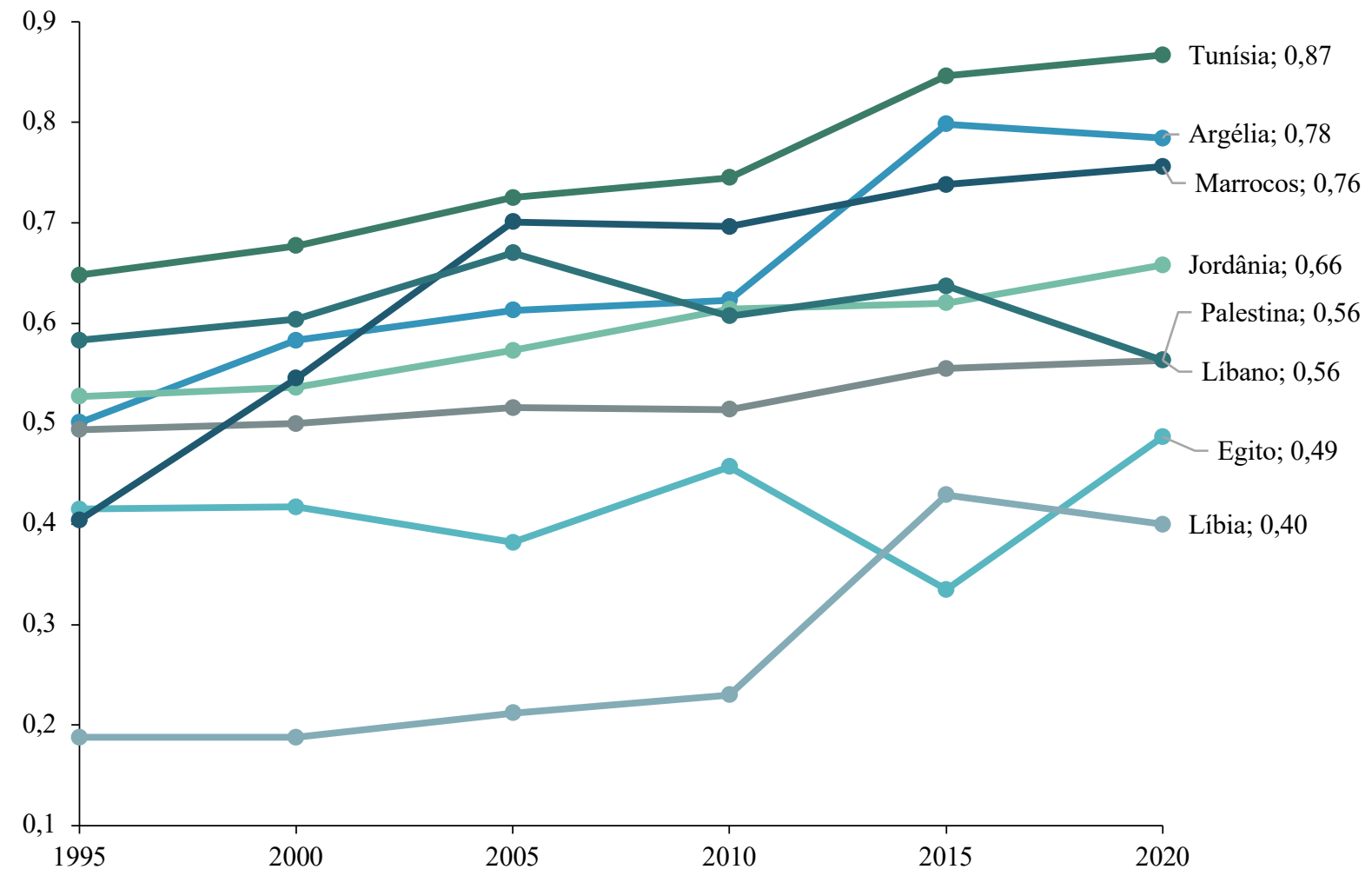

Fonte: V-Dem Dataset v11.1 (Coppedge et al., 2021).

17 Embora os territórios palestinianos incluam também a Faixa de Gaza, tendo em conta a indisponibilidade de dados, este estudo considera apenas as informações relativas ao território palestiniano da Cisjordânia. 
Atentando na distribuição dos valores pelas três dimensões (Figura 3), é possível obter uma visão mais matizada do empoderamento político das mulheres nos oito países, permitindo compreender, por exemplo, o motivo pelo qual o Egito, o país da região com a maior percentagem de mulheres no parlamento, apresenta níveis de empoderamento político mais baixos do que o Líbano, onde a representação parlamentar feminina é de apenas 5\% (IPU, 2021). De acordo com os dados do WPEl, este contraste é explicado pelo facto de a fraca participação política das mulheres no Líbano $(0,33)$ ser compensada pela sua forte participação na sociedade civil $(0,87)$ chegando a ultrapassar os valores para a Tunísia e Marrocos -, ao contrário do Egito $(0,31)$, onde as liberdades civis das mulheres também são mais reduzidas $(0,46)$.

Figura 3. Dimensões do empoderamento político das mulheres, MONA, 2020

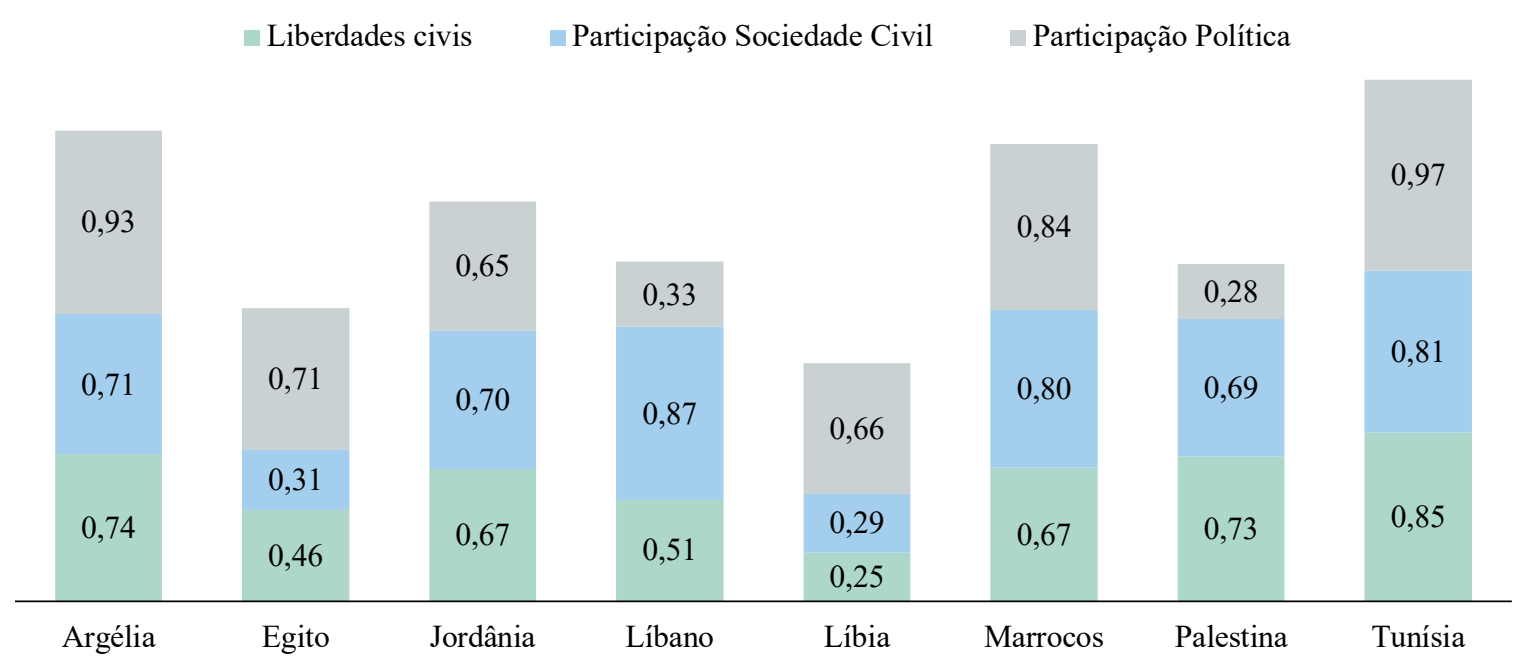

Fonte: V-Dem Dataset v11.1 (Coppedge et al., 2021).

A participação política é, efetivamente, a dimensão com valores mais elevados em quase todos os países, aproximando-se do valor máximo na Tunísia $(0,97)$ e Argélia $(0,93)$. A exceção é não só o Líbano, mas também a Jordânia $(0,65)$ e a Palestina $(0,28)$, onde a participação na sociedade civil e as liberdades civis sobressaem, ainda 
que permaneçam distantes do valor máximo. Na Líbia, estas duas dimensões apresentam valores muito baixos (inferiores a 0,3 ).

De seguida, observemos o comportamento dos indicadores que compõem cada uma das três dimensões do empoderamento político das mulheres.

\subsubsection{LIBERDADES CIVIS}

Poucos países fizeram progressos substanciais e contínuos nesta dimensão (Figura 4), mesmo na Argélia e Palestina, onde a maior evolução se deu ao nível da liberdade de movimento dentro do país e da liberdade face ao trabalho forçado (ver Anexo A). A Tunísia registou uma expansão do acesso à justiça para as mulheres a partir de 2010, enquanto o Egito presenciou uma mudança no sentido contrário. Na Líbia, as liberdades civis das mulheres mantiveram-se muito baixas e entraram em declínio em quase todos os indicadores partir de 2015. O acesso igual, seguro e efetivo à justiça pelas mulheres tem um carácter muito limitado em todos os países, sendo que apenas na Tunísia sofreu melhorias significativas, enquanto em Marrocos se

Figura 4. Liberdades civis das mulheres, MONA, 1995-2020

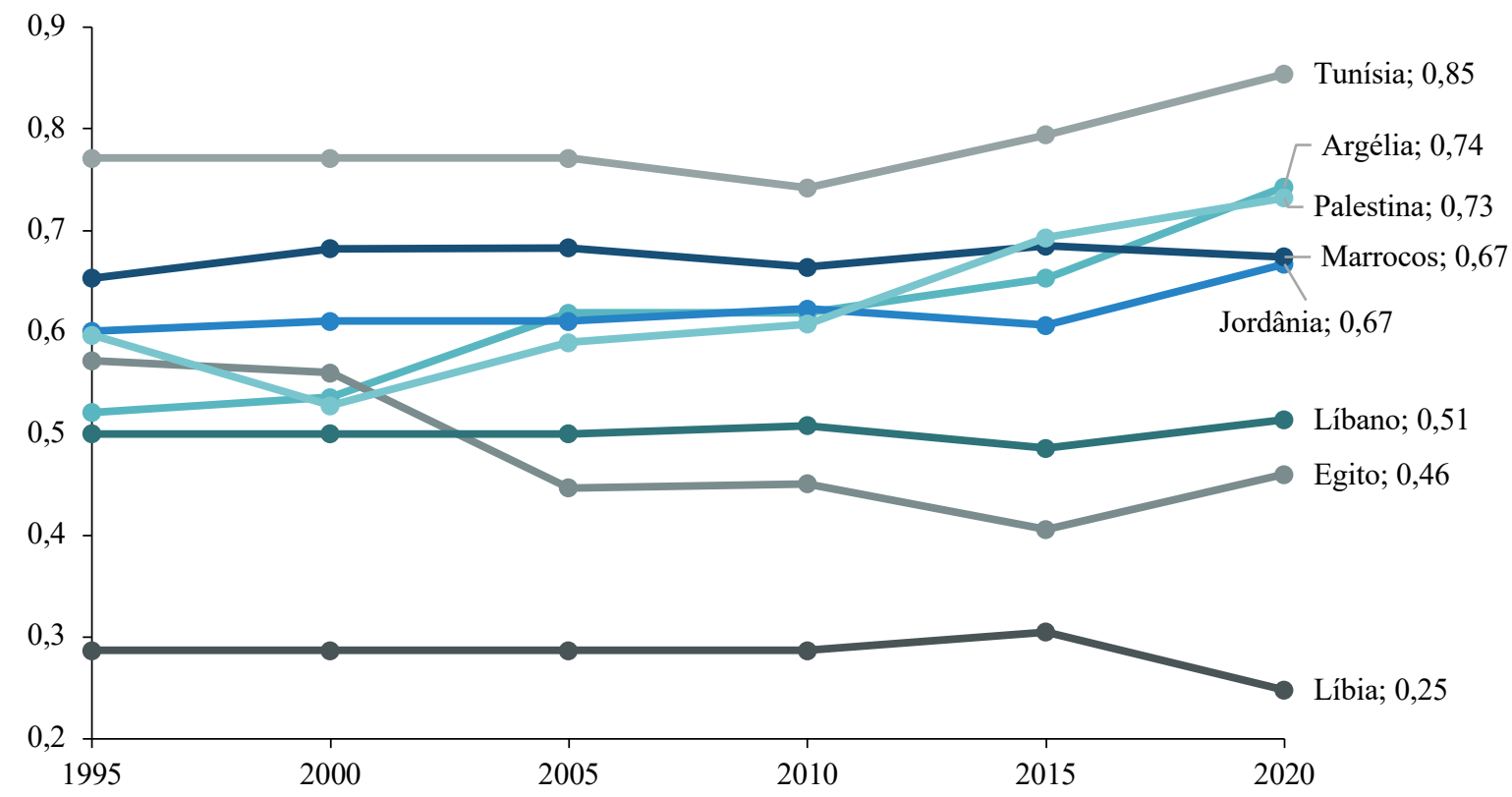


estabilizou e manteve mais alto do que na maioria dos países. Inversamente, nos oito países, apenas uma minoria de mulheres não possui direitos de propriedade.

\subsubsection{PARTICIPAÇÃO NA SOCIEDADE CIVIL}

A participação na sociedade civil subiu consideravelmente entre 2010 e 2015 (Figura

5), sobretudo nos países do Norte de África, como Marrocos $(+0,33)$, Argélia $(+0,32)$

e Tunísia $(+0,30)$. É na percentagem de mulheres jornalistas e na liberdade de discussão das mulheres que se nota a maior evolução (ver Anexo B), sobretudo na Tunísia, onde a liberdade de discussão de assuntos políticos em espaços públicos e privados é respeitada na maioria dos casos e a percentagem de mulheres nos meios de comunicação social ronda os $60 \%$. Por seu turno, o Egito manteve valores muito baixos em todo o período, que se acentuaram a partir de 2010. Apesar do enorme progresso registado na Líbia $(+0,23)$, a capacidade de participação das mulheres na sociedade civil permanece muito reduzida (0,29 em 2020). Finalmente, apesar dos valores baixos registados noutras dimensões do empoderamento político das mulheres, o Líbano é o país com níveis mais elevados de participação cívica das mulheres $(0,87$ em 2020), sobretudo no que diz respeito à participação nas organizações da sociedade civil.

Figura 5. Participação das mulheres na sociedade civil, MONA, 1995-2020.

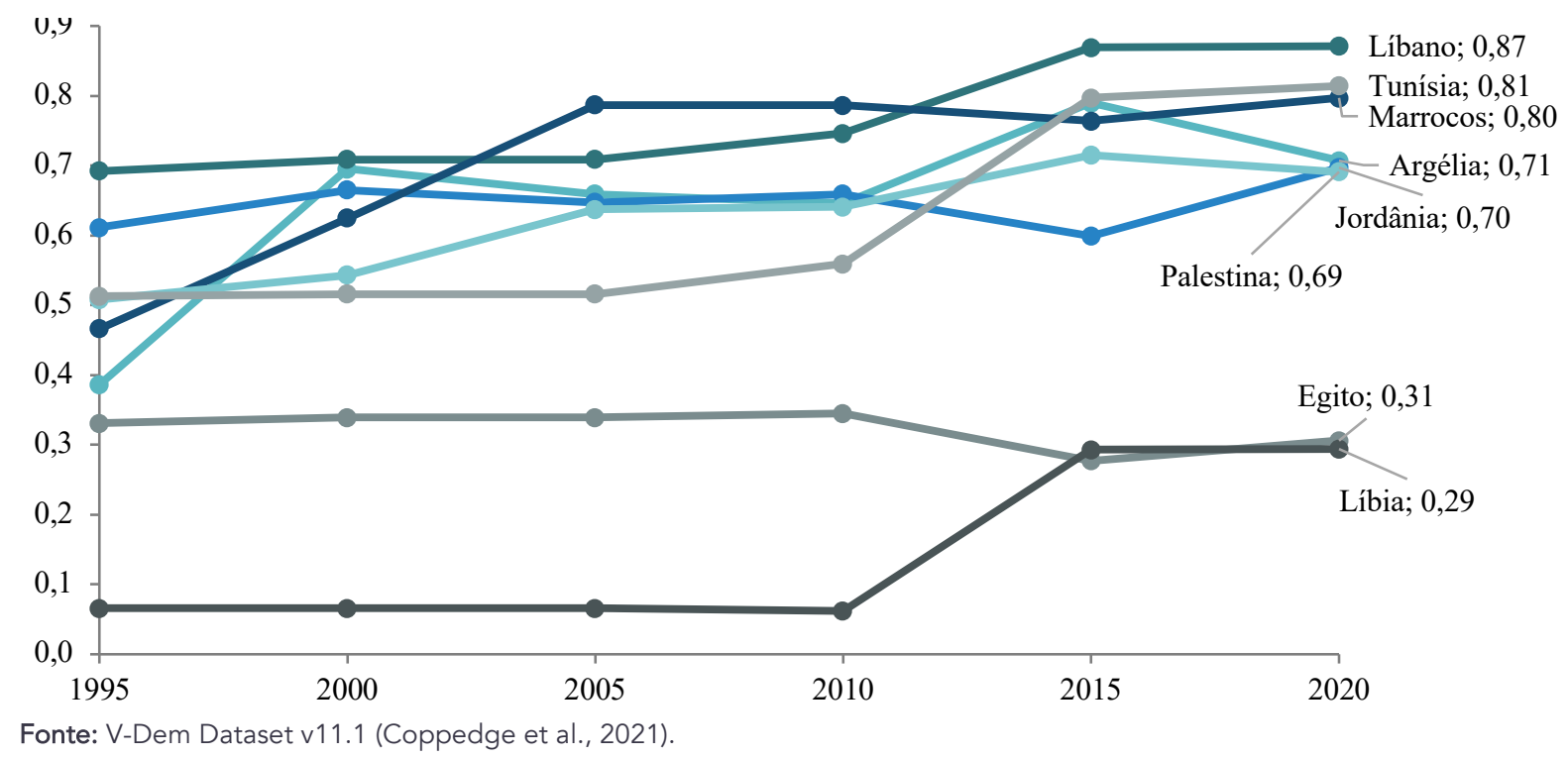




\subsubsection{PARTICIPAÇÃO POLÍTICA}

Nesta dimensão, Marrocos foi o país com o maior progresso $(+0,74)$, iniciado antes do novo milénio, quando apresentava os níveis mais baixos de participação política feminina (Figura 6). Esta rápida expansão é explicada pelo aumento da percentagem de mulheres no parlamento (de 0,6\% em 2000 para 20,5\% em 2020), enquanto a distribuição do poder por género se manteve desigual (ver Anexo C). Já na Tunísia (e, em menor medida, na Argélia), a maior representação parlamentar foi acompanhada de uma alteração gradual na distribuição do poder. Na Palestina, sucedeu o contrário, com as mulheres a perderem grande parte do poder e influência conquistados nas décadas anteriores. Por seu turno, o Egito, a Jordânia e a Líbia, com valores muito baixos noutras dimensões do empoderamento político, têm pontuações relativamente altas no domínio da participação política, devido à percentagem de mulheres nos parlamentos nacionais: $16 \%$ na Líbia e $15 \%$ no Egito e na Jordânia em 2020, um progresso relevante tendo em conta a ausência total ou parcial de mulheres deputadas no início do milénio.

Figura 6. Participação política das mulheres, MONA, 1995-2020

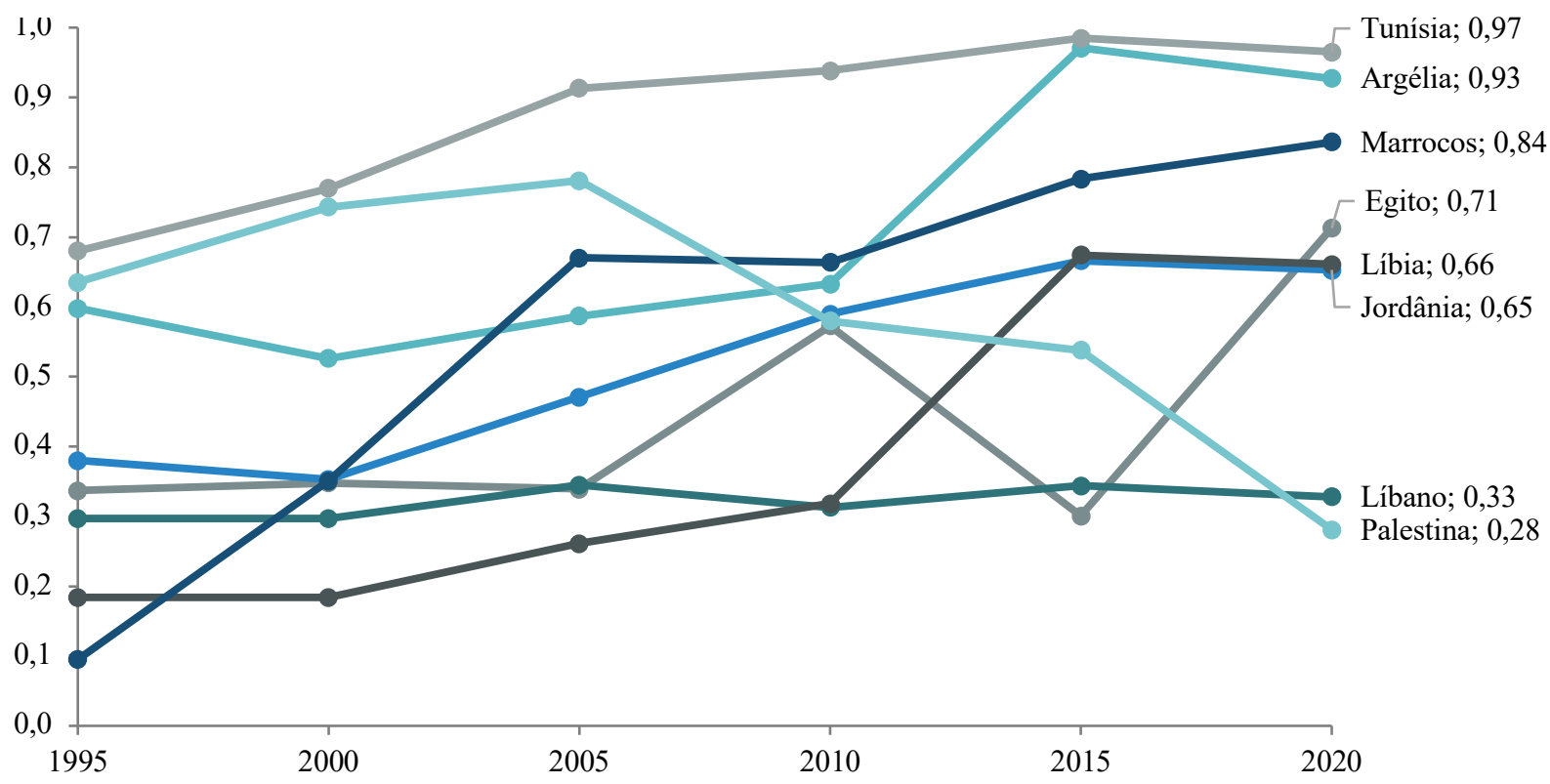

Fonte: V-Dem Dataset v11.1 (Coppedge et al., 2021). 


\section{Conclusões}

Uma das consequências do florescimento dos estudos comparados de género e política foi o desenvolvimento de um pluralismo metodológico num campo de estudo onde as abordagens qualitativas proliferavam. Porém, as análises quantitativas desenvolvidas revelam um enfoque restrito, incidindo quase exclusivamente sobre a representação descritiva das mulheres nos parlamentos, em harmonia com a tradição feminista liberal (Arat, 2015). Essa orientação resulta, em grande medida, das limitações impostas pela disponibilidade, qualidade e consistência dos dados (Tripp \& Hughes, 2018).

Desse modo, o recurso aos índices de género produzidos por organizações internacionais como as Nações Unidas, o Fórum Económico Mundial ou a OCDE é justificado pela sua elevada cobertura espacial. Contudo, o uso destas medidas no plano académico tem sido objeto de inúmeras críticas, sobretudo pela visão reducionista do empoderamento político das mulheres que oferecem e pela incapacidade de incorporar uma perspetiva interseccional (Hughes \& Dubrow, 2018) e global (Medie \& Kang, 2018).

Neste artigo, tentei demonstrar a pertinência e adequabilidade do Índice do Empoderamento Político das Mulheres (WPEI) do V-Dem relativamente aos índices de género mais conhecidos. Embora constitua uma medida mais precisa e abrangente do empoderamento político das mulheres, o WPEI não resolve todos os problemas aqui discutidos, apresentando algumas limitações. Primeiro, como reconhecem os seus autores, o índice não capta as diferenças baseadas na região, classe, sexualidade, racialização ou etnicidade entre mulheres do mesmo país (Sundström et al., 2017). Por esse motivo, é uma medida pouco útil para uma análise interseccional do empoderamento político das mulheres, ainda que as variáveis incluídas se revelem adequadas a diferentes contextos políticos, sociais e culturais. 
Segundo, o índice não inclui variáveis sobre a representação das mulheres no governo, nas comissões parlamentares, nos órgãos de poder local, na diplomacia ou nos tribunais, não obstante a importância destas esferas de atuação para a tomada de decisão (Alexander et al., 2018). A dimensão da participação política das mulheres pode ser alargada de forma a incluir estas dimensões, bem como a participação feminina nos processos de paz e construção do estado, tendo em conta a influência dos conflitos armados para o empoderamento das mulheres (Dahlum \& Wig, 2020; Webster et al., 2019).

Terceiro, a dimensão das liberdades civis não inclui fatores determinantes para a autonomia das mulheres, como os direitos sexuais e reprodutivos (por exemplo, o direito ao aborto e o acesso a cuidados de saúde) ou o acesso à cidadania nacional. Além disso, outra dimensão a considerar é a (in)segurança das mulheres, refletida na prevalência de violência sexual e de género, devido aos constrangimentos que impõe sobre a agência das mulheres (Ertan et al., 2018). Neste sentido, o SIGI pode ser utilizado como complemento ao WPEI, uma vez que oferece dados recentes sobre a integridade física das mulheres. 


\section{Bibliografia}

Alexander, A. C., Bolzendahl, C., \& Jalalzai, F. (2018). Measuring Women's Political Empowerment across the Globe: Strategies, Challenges and Future Research. Cham: Palgrave Macmillan.

Arat, Z. F. K. (2015). Feminisms, Women's Rights, and the UN: Would Achieving Gender Equality Empower Women? American Political Science Review, 109(4), 674-689.

Bonfils, L. de, Humbert, A. L., Ivaškaite-Tamošiune, V., Manca, A. R., Nobrega, L., Reingarde, J., \& Lestón, I. R. (2016). Gender Indices. In In A. Wong, M. Wickramasinghe, R. Hoogland, \& N.A. Naples (Eds.), The Wiley Blackwell Encyclopedia of Gender and Sexuality Studies.

Branisa, B., Klasen, S., Ziegler, M., Drechsler, D., \& Jütting, J. (2014). The Institutional Basis of Gender Inequality: The Social Institutions and Gender Index (SIGI). Feminist Economics, 20(2), 29-64.

Coppedge, M., Gerring, J., Knutsen, C. H., Lindberg, S. I., Teorell, J., Altman, D., ... Ziblatt, D. (2021). V-Dem Country-Year Dataset v11.1. Varieties of Democracy (VDem) Project. www.v-dem.net/en/data/data/v-dem-dataset-v111

Crenshaw, K. (1991). Mapping the Margins: Intersectionality, Identity Politics, and Violence against Women of Color. Stanford Law Review, 43(6), 1299.

Dahlum, S., \& Wig, T. (2020). Peace Above the Glass Ceiling: The Historical Relationship between Female Political Empowerment and Civil Conflict. International Studies Quarterly, 64(4), 879-893.

Ertan, S., Monroy, C., Vallejo, J. P., Romero, G., \& Erazo, A. C. (2018). The Status of Women's Political Empowerment Worldwide. In A. C. Alexander, C. Bolzendahl, \& F. Jalalzai (Eds.), Measuring Women's Political Empowerment across the Globe (pp. 55-76). Cham: Palgrave Macmillan.

Gaye, A., Klugman, J., Kovacevic, M., Twigg, S., \& Zambrano, E. (2010). Measuring Key Disparities in Human Development: The Gender Inequality Index. New York: United Nations Development Programme (UNDP).

Hughes, M. M. (2019). Crossing intersections: Overcoming the challenges of crossnational research on the legislative representation of women from marginalized 
groups. In J. Dubrow (Ed.), Political Inequality in an Age of Democracy: Crossnational Perspectives (pp. 51-66). New York: Routledge.

Hughes, M. M., \& Dubrow, J. K. (2018). Intersectionality and Women's Political Empowerment Worldwide. In A. C. Alexander, C. Bolzendahl, \& F. Jalalzai (Eds.), Measuring Women's Political Empowerment across the Globe (pp. 77-96). Cham: Palgrave Macmillan.

IPU - Inter-Parliamentary Union. (2021). Parline - global data on national parliaments. https://data.ipu.org/content/parline-global-data-national-parliaments

Karim, S., \& Hill, D. (2018). The Study of Gender and Women in Cross-National Political Science Research: Rethinking Concepts and Measurement. San Francisco: Annual Convention of the International Studies Association.

Klugman, J., Dahl, M., \& Bakken, I. v. (2018). The Women, Peace, and Security Index: A Global Index of Women's Wellbeing. Oslo: Peace Research Institute Oslo (PRIO).

Medie, P. A., \& Kang, A. J. (2018). Power, knowledge and the politics of gender in the Global South. European Journal of Politics and Gender, 1(1-2), 37-54.

Moghadam, V. M., \& Senftova, L. (2005). Measuring women's empowerment: Participation and rights in civil, political, social, economic, and cultural domains. International Social Science Journal, 57(184), 389-412.

OCDE. (2019). SIGI 2019 Global Report: Transforming Challenges into Opportunities.

Paxton, P., Kunovich, S., \& Hughes, M. M. (2007). Gender in Politics. Annual Review of Sociology, 33, 263-284.

Paxton, P. M. M., \& Hughes, M. M. (2014). Women, Politics, and Power: A Global Perspective (2nd ed.). SAGE Publications.

Sundström, A., Paxton, P., Wang, Y. T., \& Lindberg, S. I. (2017). Women's Political Empowerment: A New Global Index, 1900-2012. World Development, 94, 321335.

Tripp, A. M., \& Hughes, M. M. (2018). Methods, methodologies and epistemologies in the study of gender and politics. European Journal of Politics and Gender, 1(12), 241-257.

UNDP. (2020a). Human Development Report 2020: The next frontier: Human Development and the Anthropocene. 
UNDP. (2020b). Tackling social norms: A game changer for gender inequalities.

United Nations. (1996). The Beijing Declaration and Platform for Action. United Nations.

Webster, K., Chen, C., \& Beardsley, K. (2019). Conflict, Peace, and the Evolution of Women's Empowerment. International Organization, 73(2), 255-289.

World Economic Forum. (2021). Global Gender Gap Report. 


\section{ANEXOS}

3.5. Anexo A - Liberdades civis, MONA, 2000, 2010 e 2020

Figura A1. Liberdade de movimento dentro do país

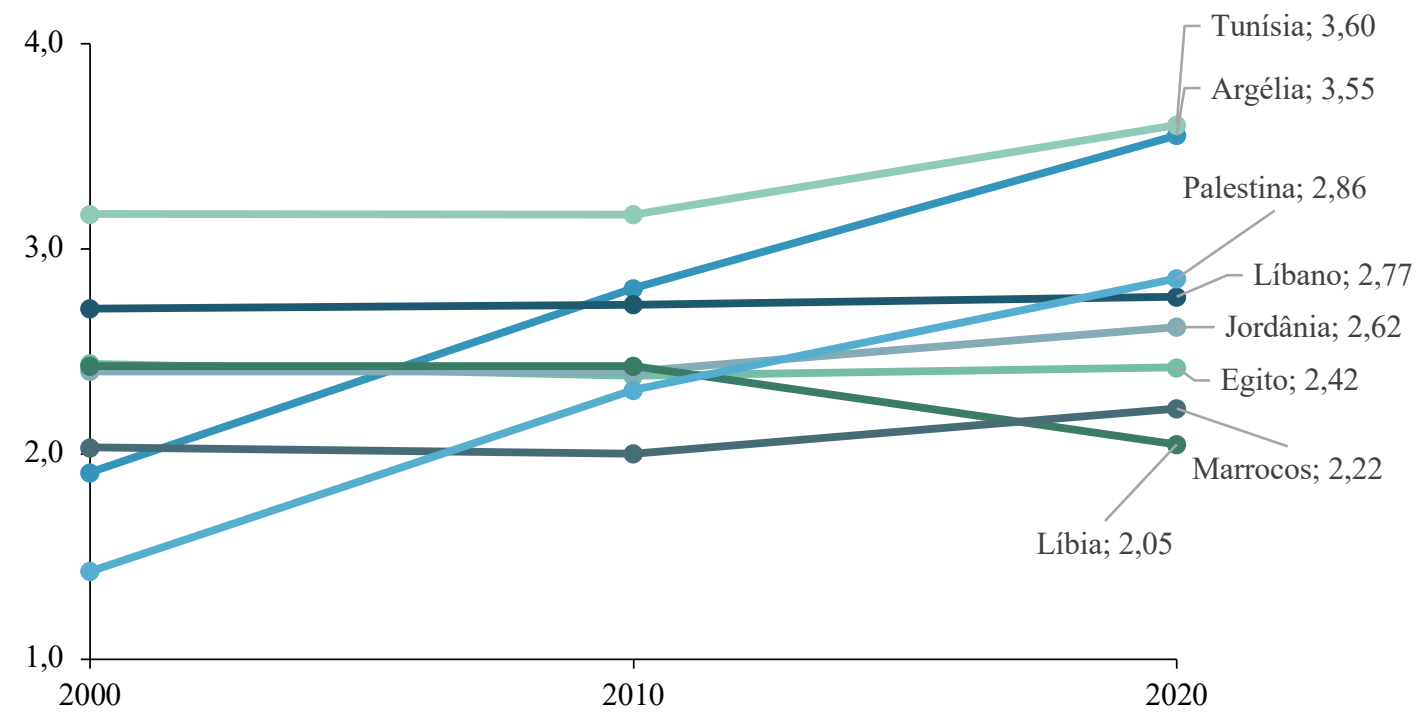

Figura A2. Liberdade face ao trabalho forçado

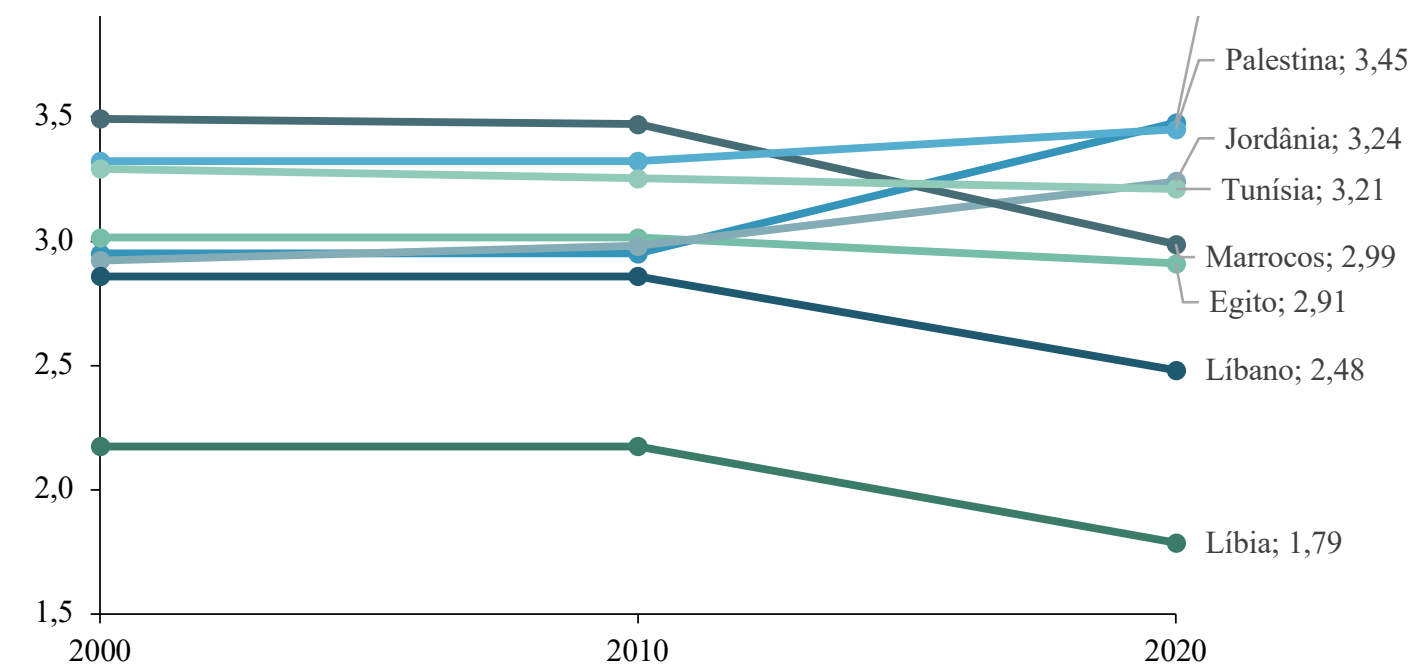


Figura A3. Direitos de propriedade

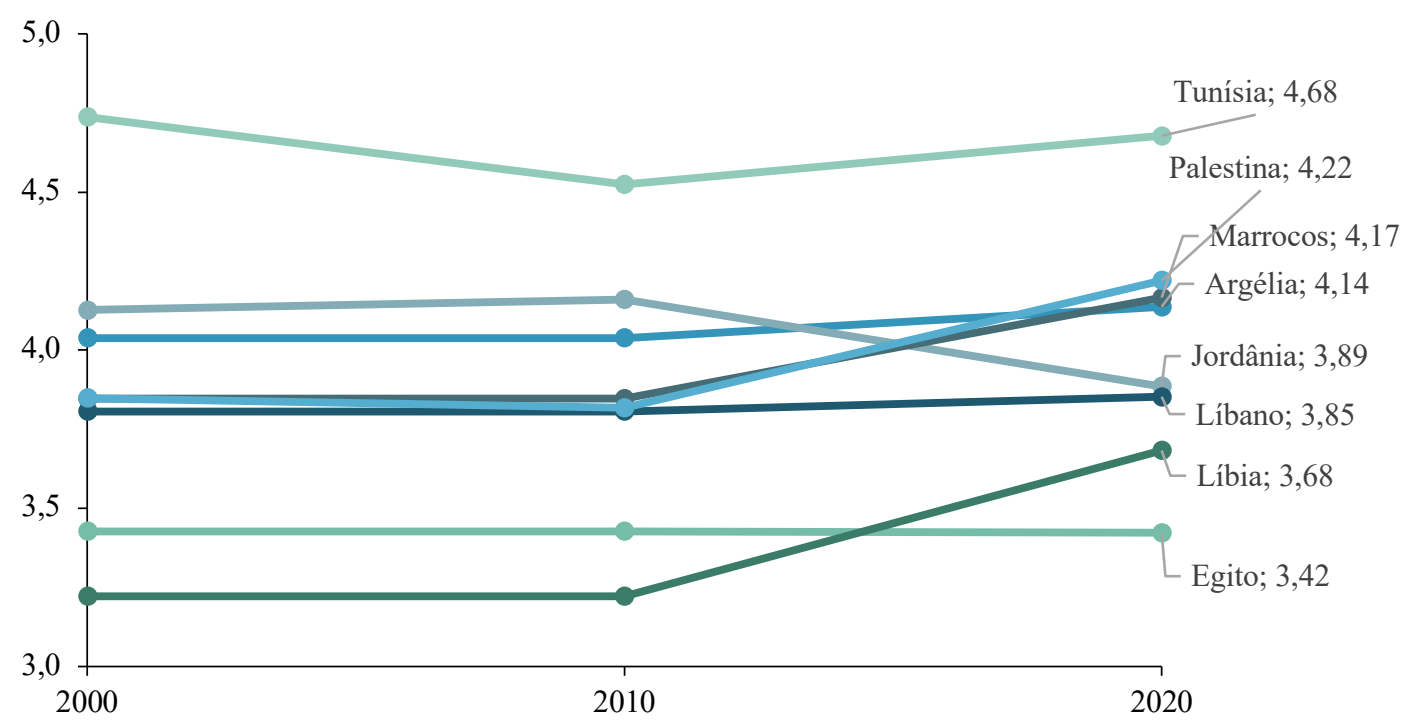

Figura A4. Acesso à justiça

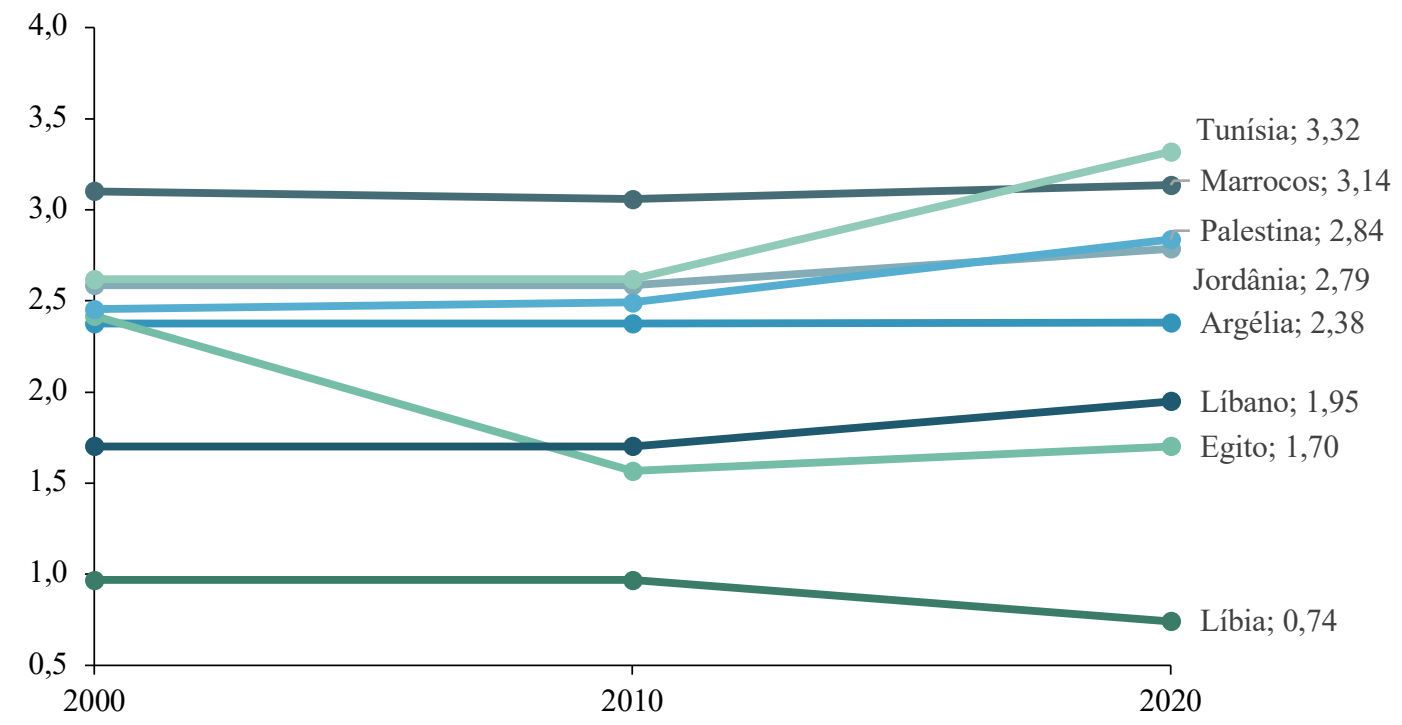


3.6. Anexo B - Participação na sociedade civil, MONA, 2000, 2010 e 2020

Figura B1. Liberdade de discussão política

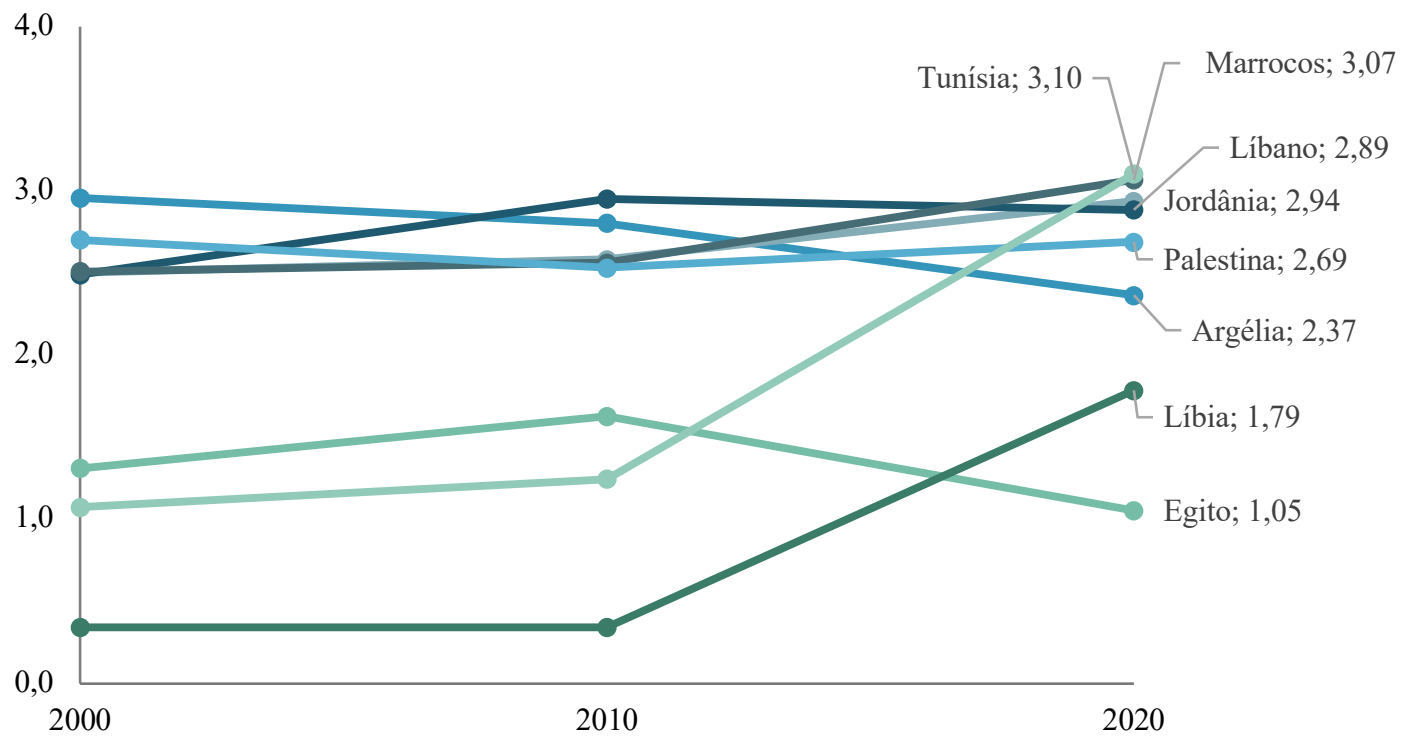

Figura B2. Participação em organizações da sociedade civil

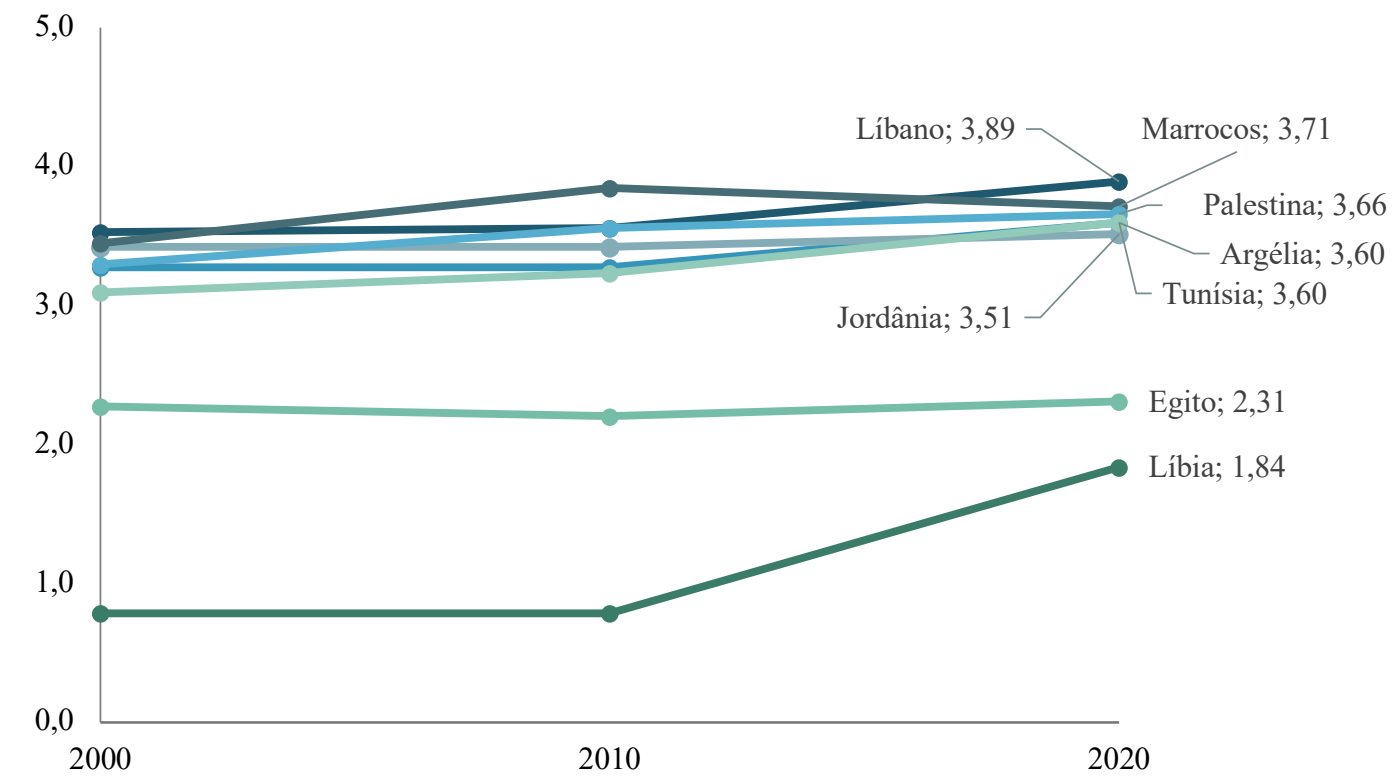


Figura B3. Mulheres jornalistas, $\%$

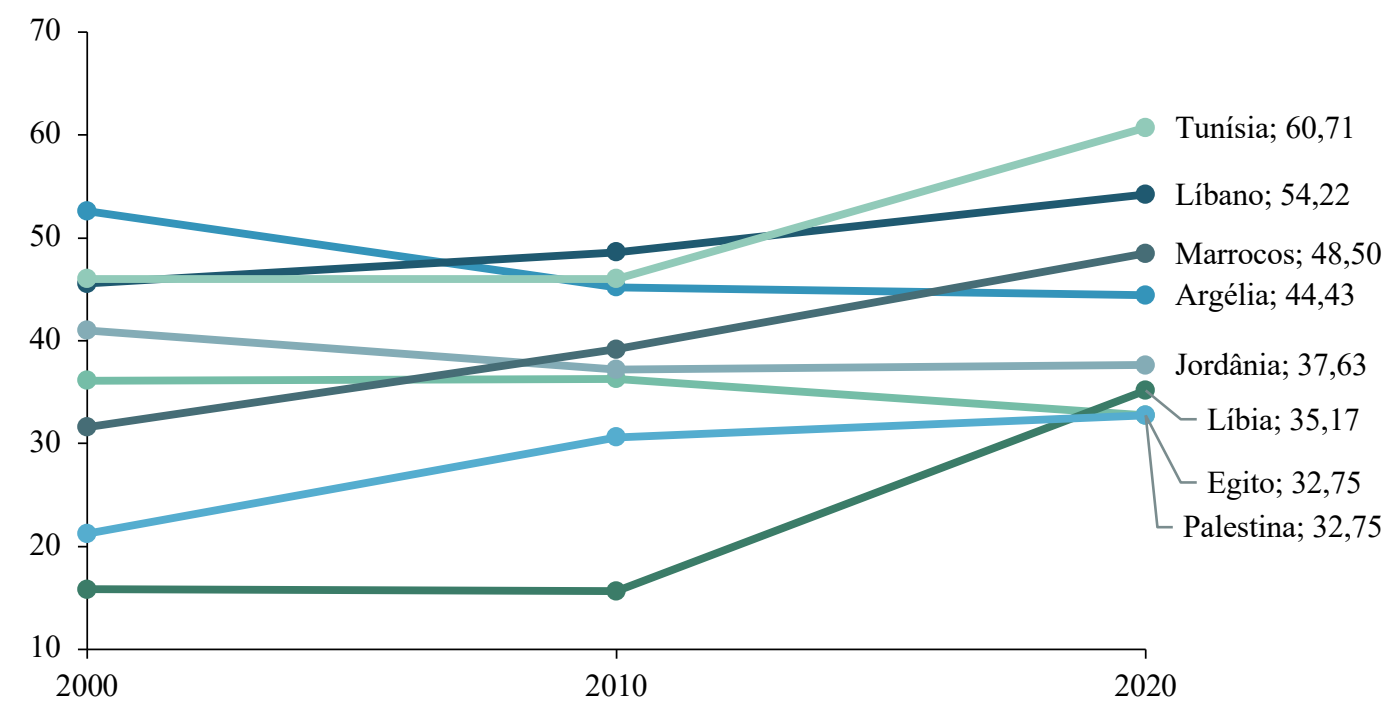


3.7. Anexo C - Participação política, MONA, 2000, 2010 e 2020

Figura C1. Mulheres no parlamento, \%

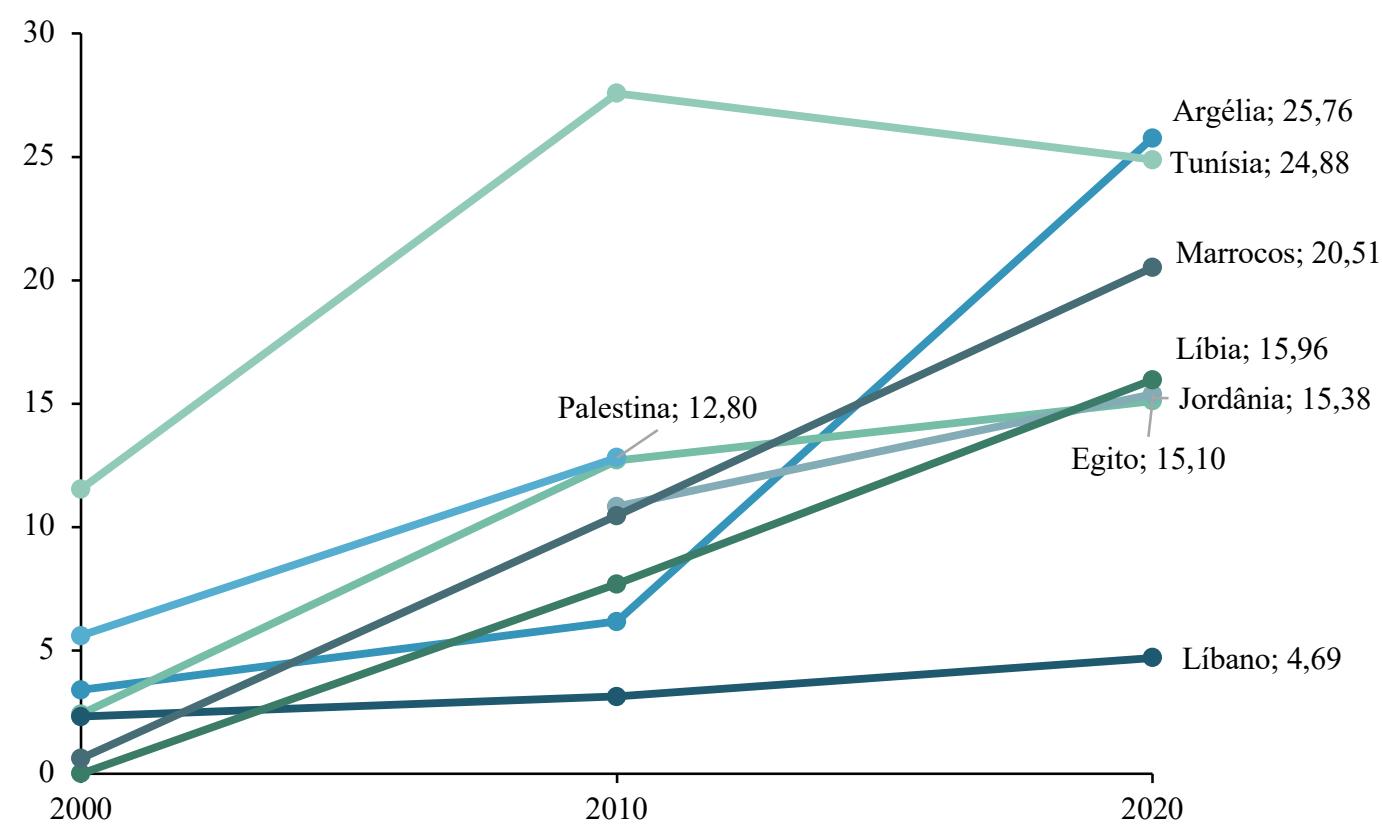

Figura C2. Distribuição do poder por género

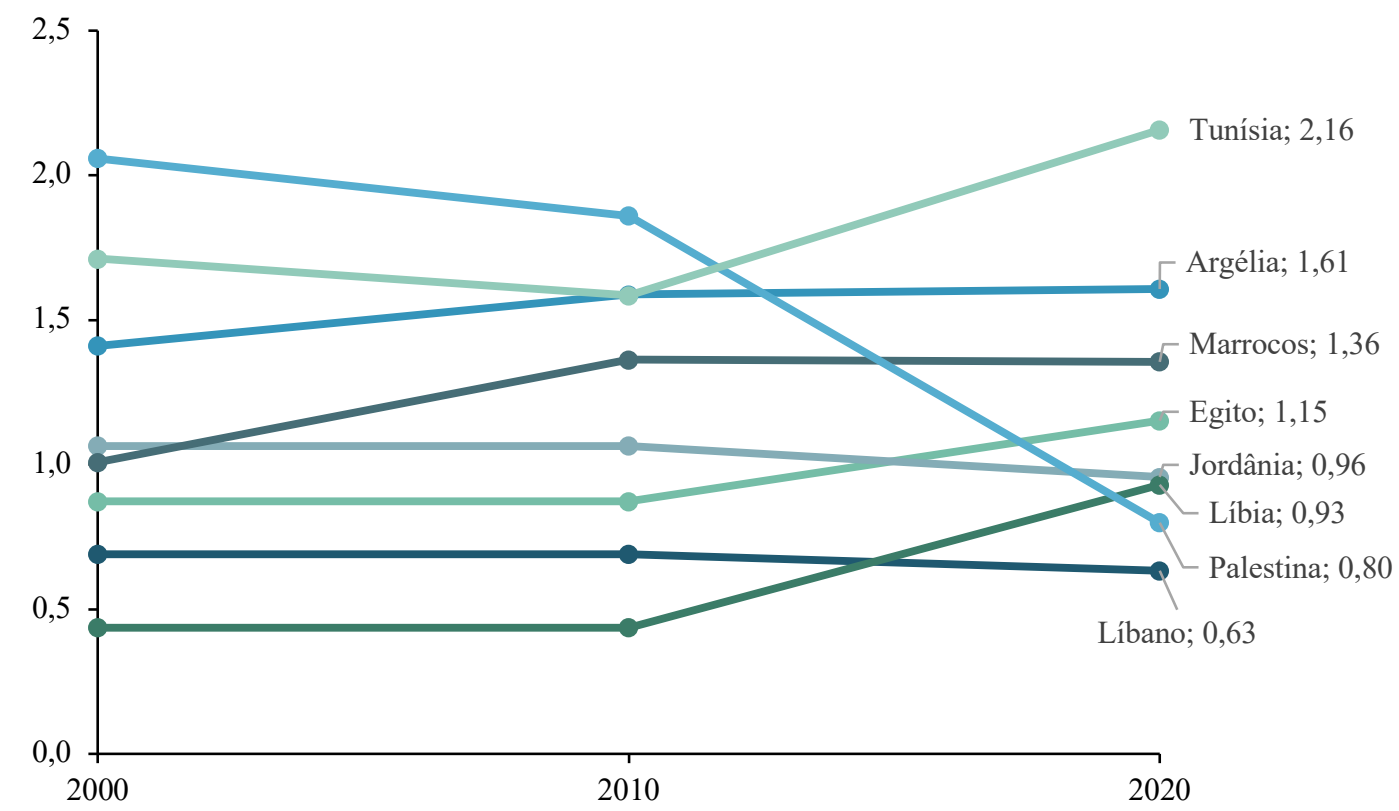

